\title{
An experimental investigation on ultra-precision instrumented smart aerostatic bearing spindle applied to high speed micro-drilling
}

\section{Chao Wang W,* $^{\mathrm{a},}$}

c.wang.1@warwick.ac.uk

\section{Kai Cheng ${ }^{\mathrm{b}}$}

Richard Rakowsk

Juliette

a'Warwick Manufacturing Group (WMG), The University of Warwick, Coventry CV4 7AL, UK

${ }^{\mathbf{b}}$ Advanced Manufacturing and Enterprise Engineering (AMEE), College of Engineering, Design and Physical Sciences, Brunel University London, Uxbridge UB8 3PH, UK

${ }^{*}$ Corresponding author.

Abstract

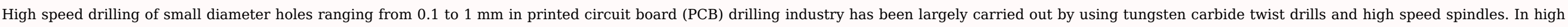

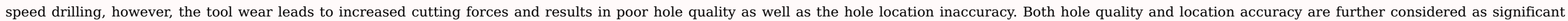

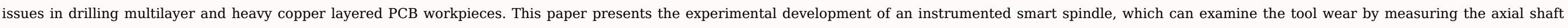

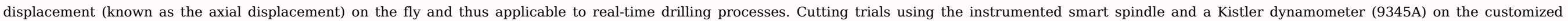

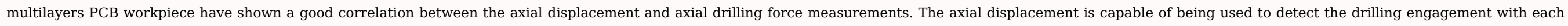
copper layer. Furthermore, the instrumented smart spindle can additionally be used to prevent a thrust bearing from being over-loaded and most importantly to detect tool wear in process.

Keywords: High speed drilling; Aerostatic bearing spindle; Micro tool wear; Instrumented smart spindle; Multilayer PCB drilling

\section{Introduction}

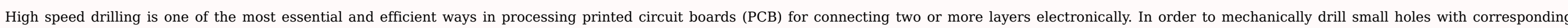

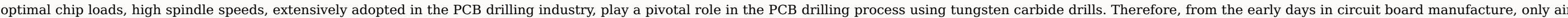
bearing technology offered the capability of attaining very high rotational speeds over long periods of unsupervised operation [1,2].

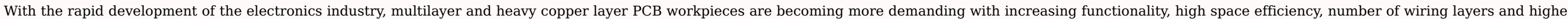

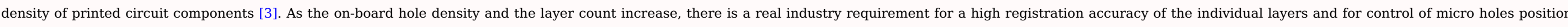

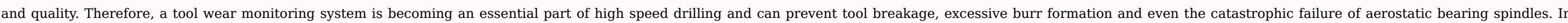

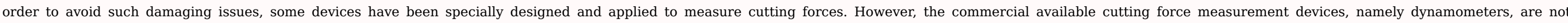

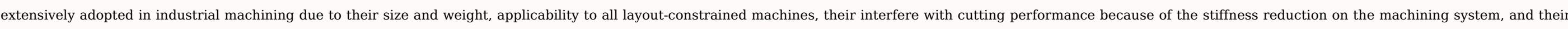

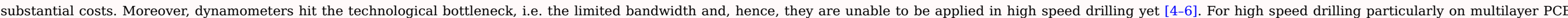

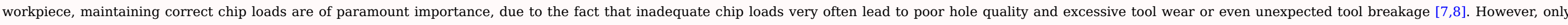
limited research has investigated methods for an instrumented smart spindle to detect tool wear in application of high speed drilling.

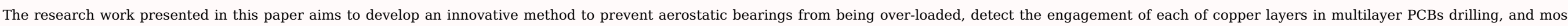




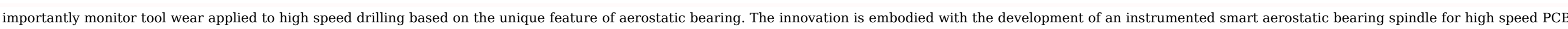

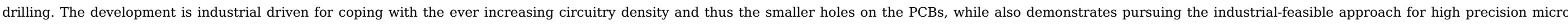
drilling, and future ultraprecision and micro machining.

\section{Experimental setup}

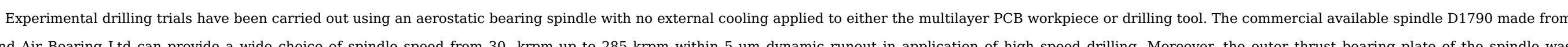

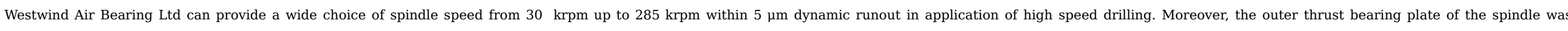

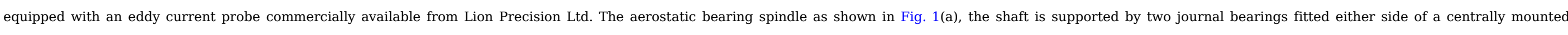

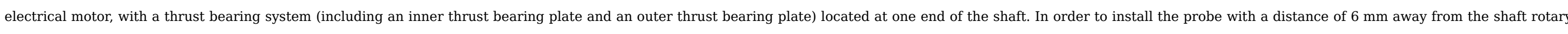

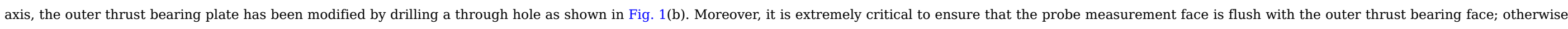

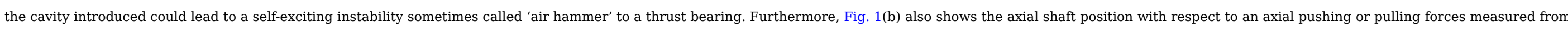

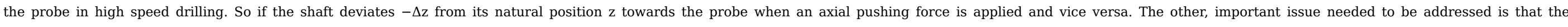

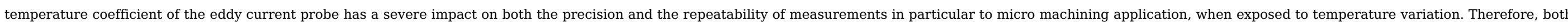

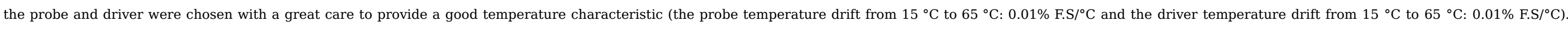

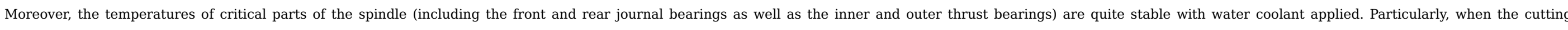

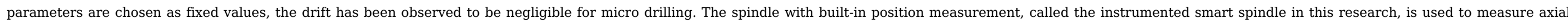
shaft displacement (also known as the axial displacement). 


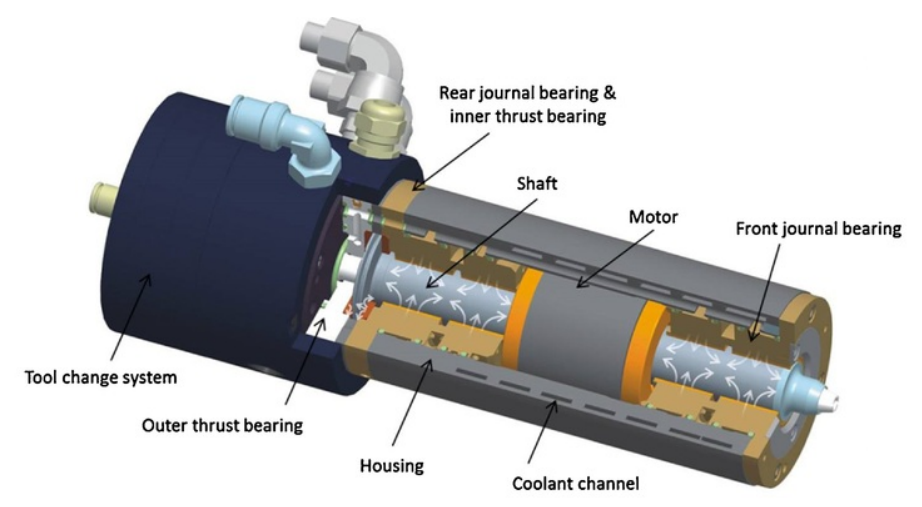

(a)

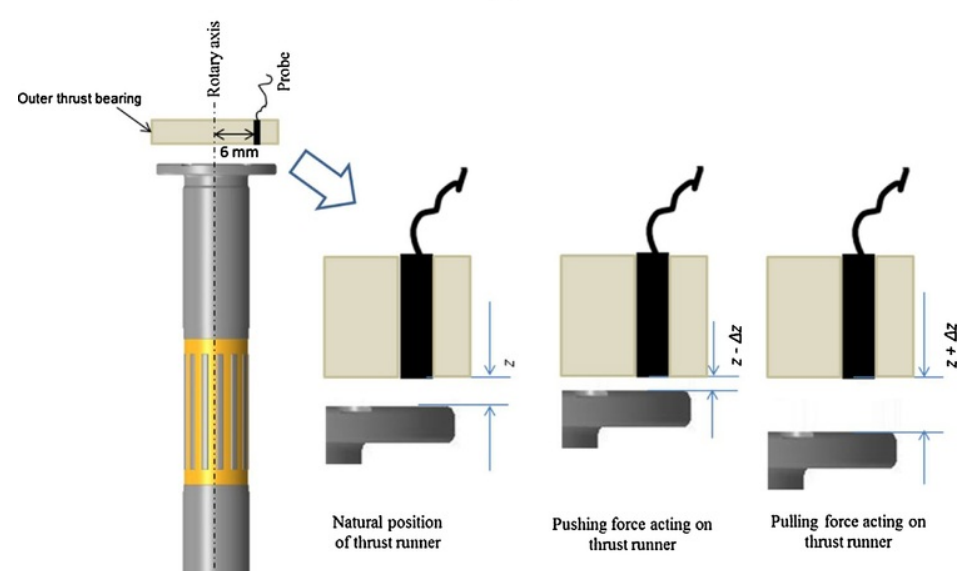

(b)

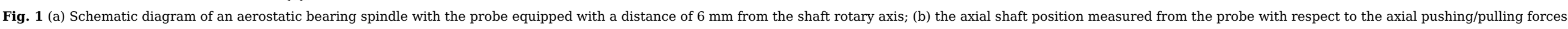
alt-text: Fig. 1

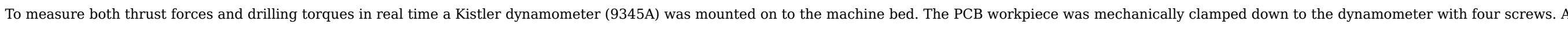

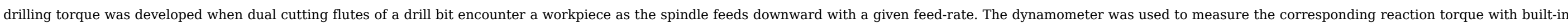

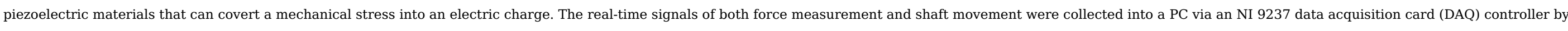

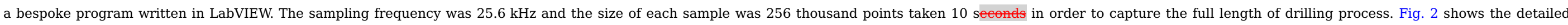
experimental setup technical specifications of the drilling system, including the micro drill, the Kistler dynamometer (9345A), the aerostatic bearing spindle and the eddy current probe. 


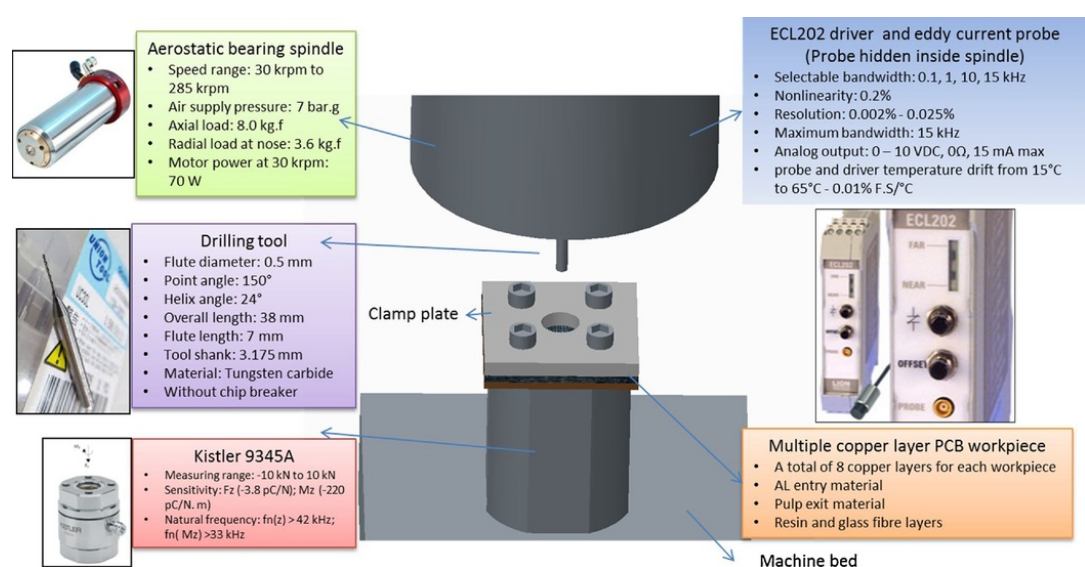

Fig. 2 Experimental setup of the high speed drilling system, including micro drill, Kistler dynamometer (9345A), aerostatic bearing spindle, and multilayer PCB workpiece. alt-text: Fig. 2

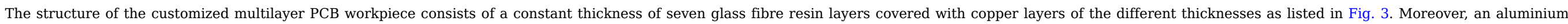

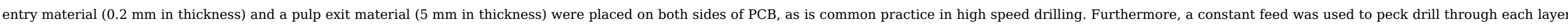
including the aluminium entry material, the copper and glass fibre resin layers, and the exit material.

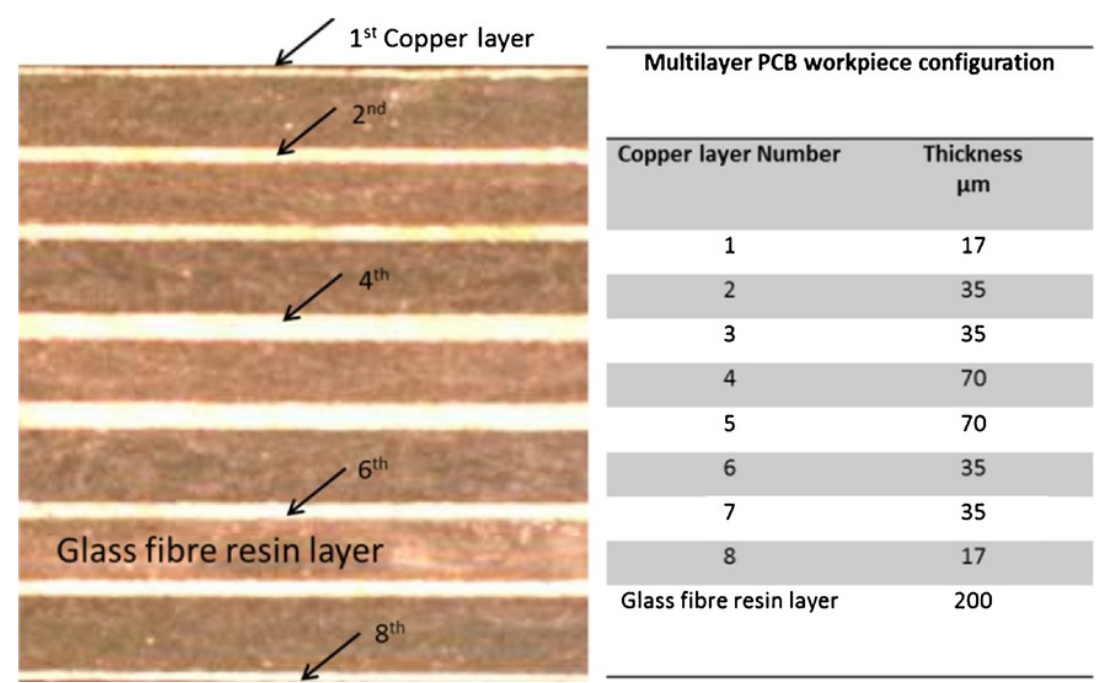

Fig. 3 Multilayer PCB workpiece configuration indicating the thickness of the copper layer and the glass fibre resin layer. alt-text: Fig. 3

\section{Results, analysis and discussion}

\subsection{Analysis of axial drilling force and drilling torque}

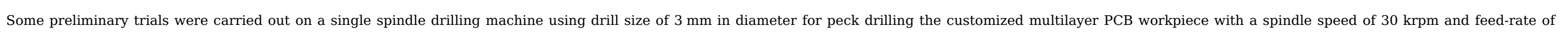

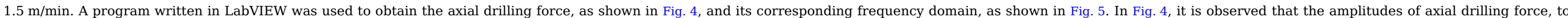




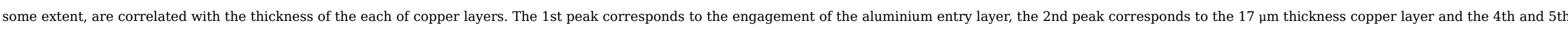

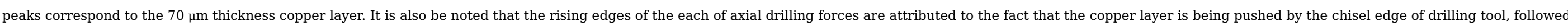

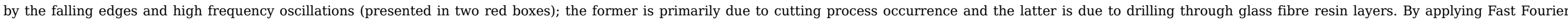

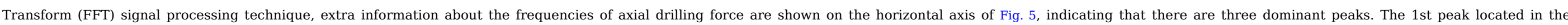

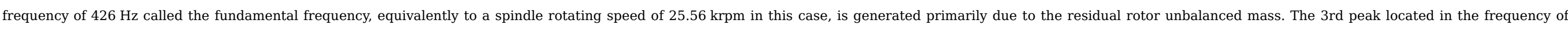

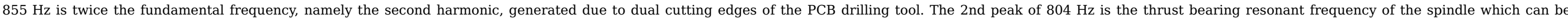
accurately detect by impact hammer testing.

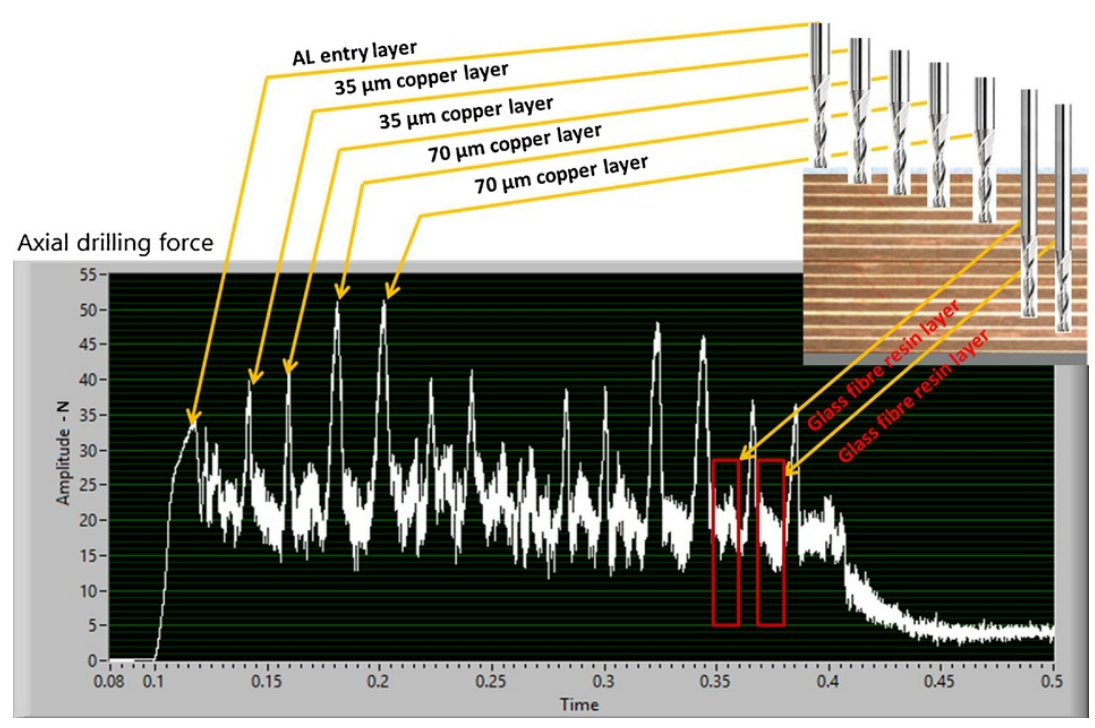

Fig. 4 A measure of axial drilling force while drilling through multilayer PCB workpiece (feed-rate of $1.5 \mathrm{~m} / \mathrm{min}$ and spindle speed of $30 \mathrm{krpm}$ ). alt-text: Fig. 4

\section{FFT of axial drilling force}

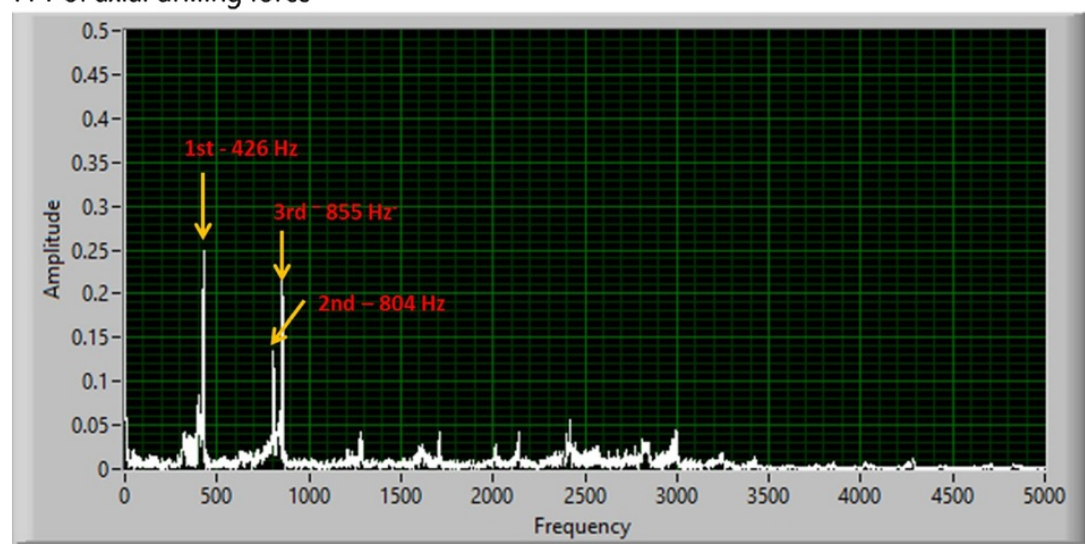

Fig. 5 Frequency domain of the axial drilling force after FFT conversion. 


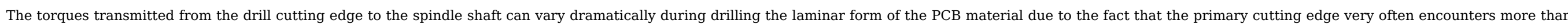

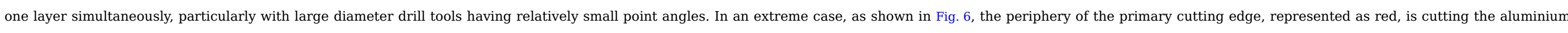

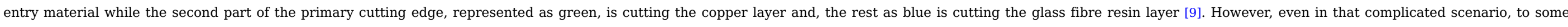

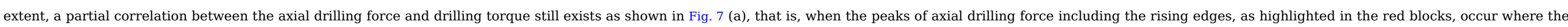

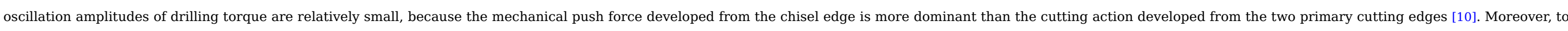

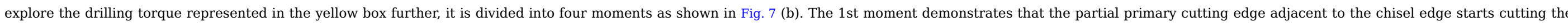

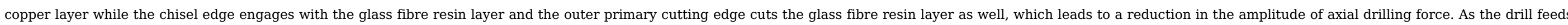

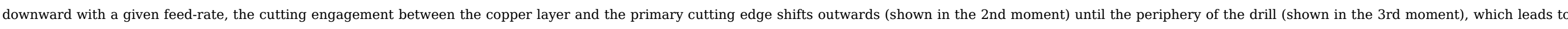

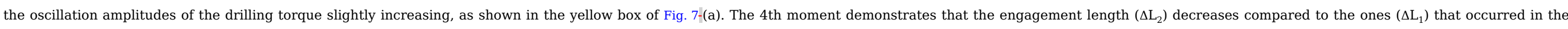

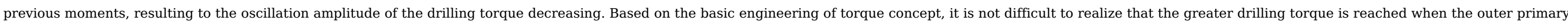

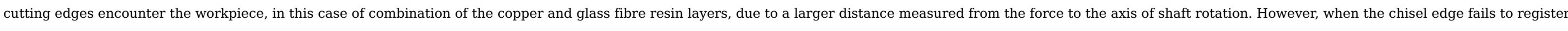

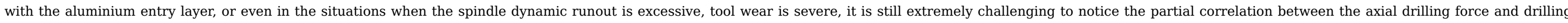
torque. Therefore, it is unlikely to explore further and find a correlation between the drilling torque and the multilayer PCB workpiece configuration.

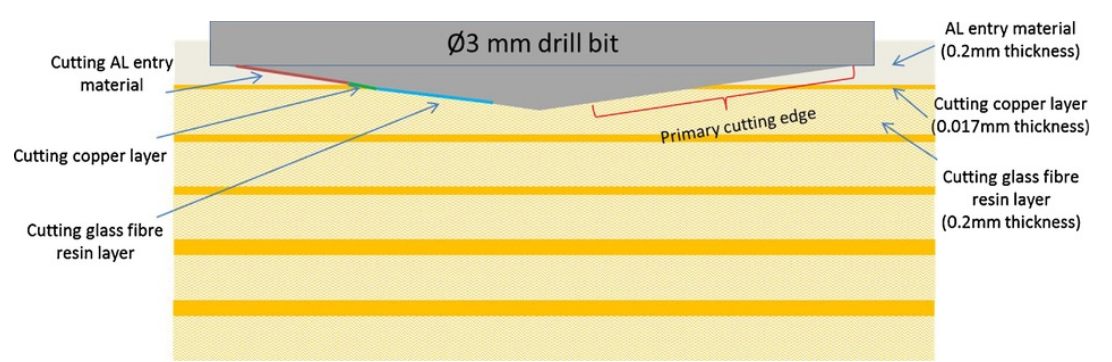

Fig. 6 Schematic diagram showing $3 \mathrm{~mm}$ diameter drill tool cutting the aluminium entry material, copper layer and glass fibre resin layer simultaneously. 


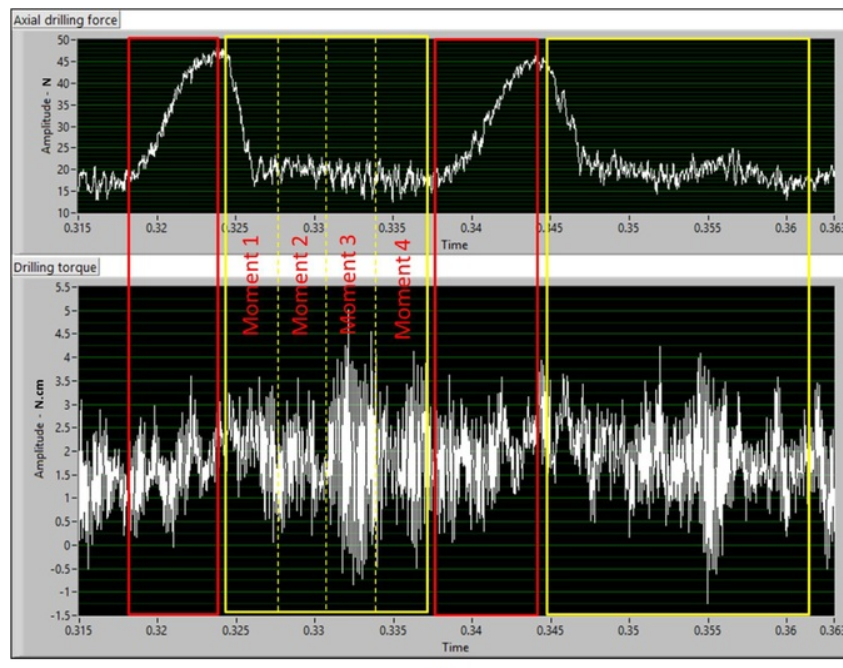

(a)

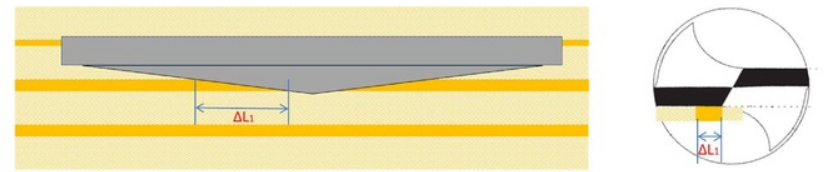

Moment 1

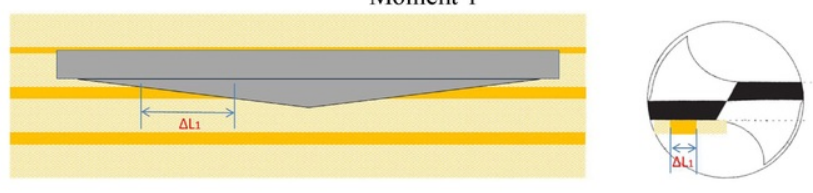

Moment 2

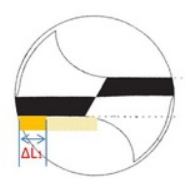

Moment 3

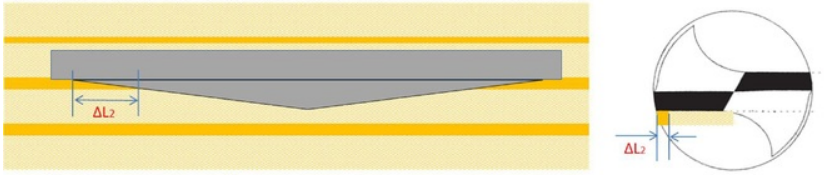

Moment 4

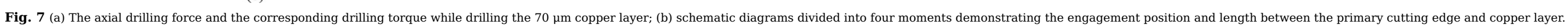
alt-text: Fig. 7

3.2 Correlation of axial displacement and axial drilling force with respect to multilayer PCB workpiece configuration 


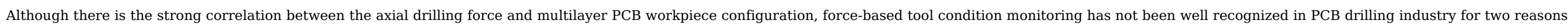

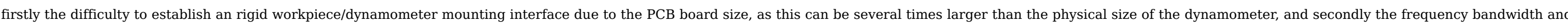

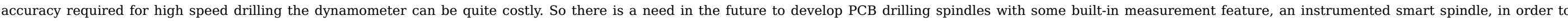

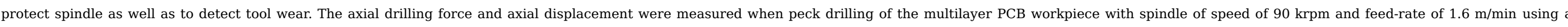

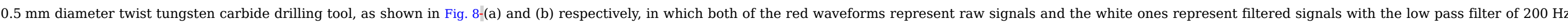

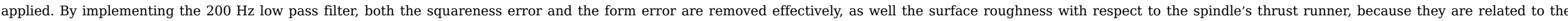

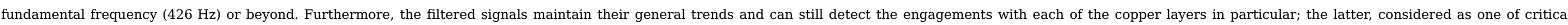
features, is analysed in the following sections.

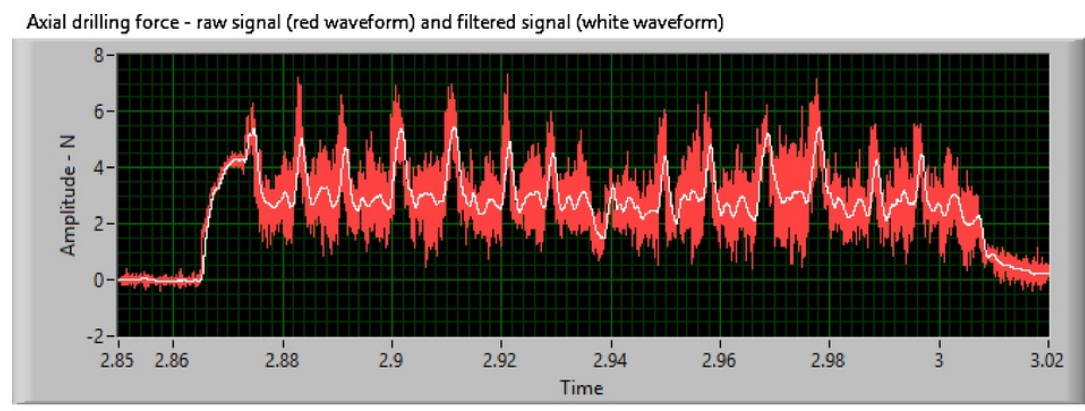

(a)

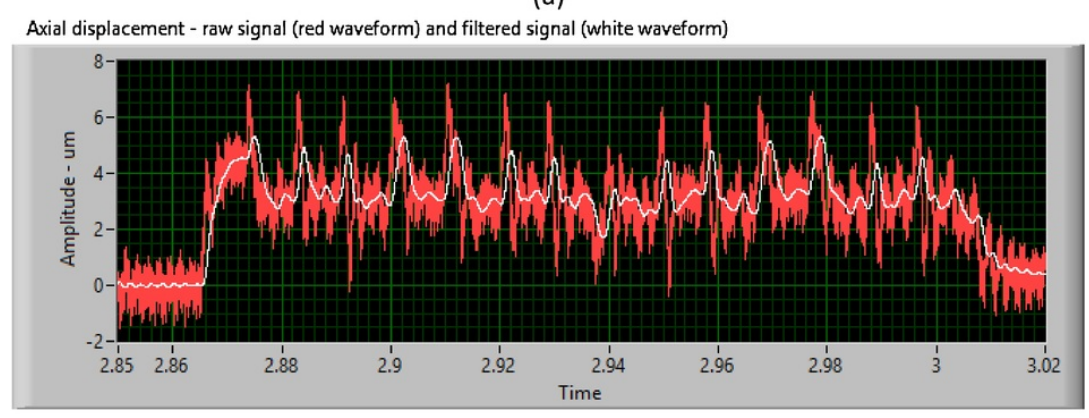

(b)

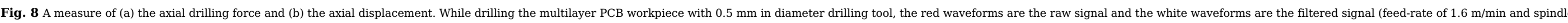
speed of $90 \mathrm{krpm}$ ). (For interpretation of the references to colour in this figure legend, the reader is referred to the web version of this article.)

alt-text: Fig. 8

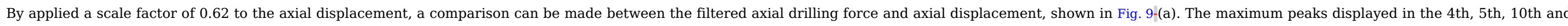

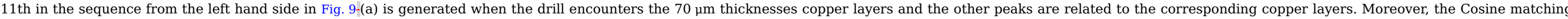

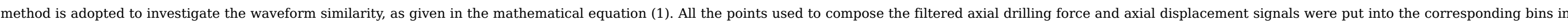

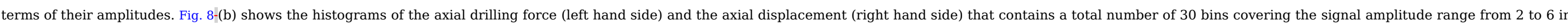

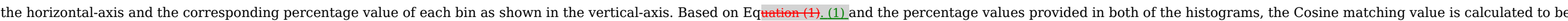

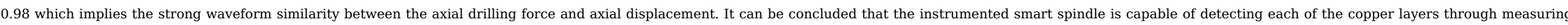

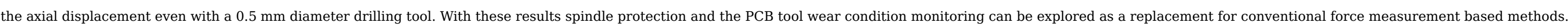




$$
\cos (a)=\frac{\sum_{i=1}^{n} \vec{x}_{x} \times \sum_{i=1}^{n} \vec{y}_{i}}{\left|\sum_{i=1}^{n} x_{i}^{2} \| \sum_{i=1}^{n} y_{i}^{2}\right|}
$$

Where $\mathrm{n}$ is the number of bins, $\cos (\underline{\mathrm{e} \alpha})$ is the waveform similarity value, where $\mathrm{x}$ represents for the first waveform and y represents the second waveform.

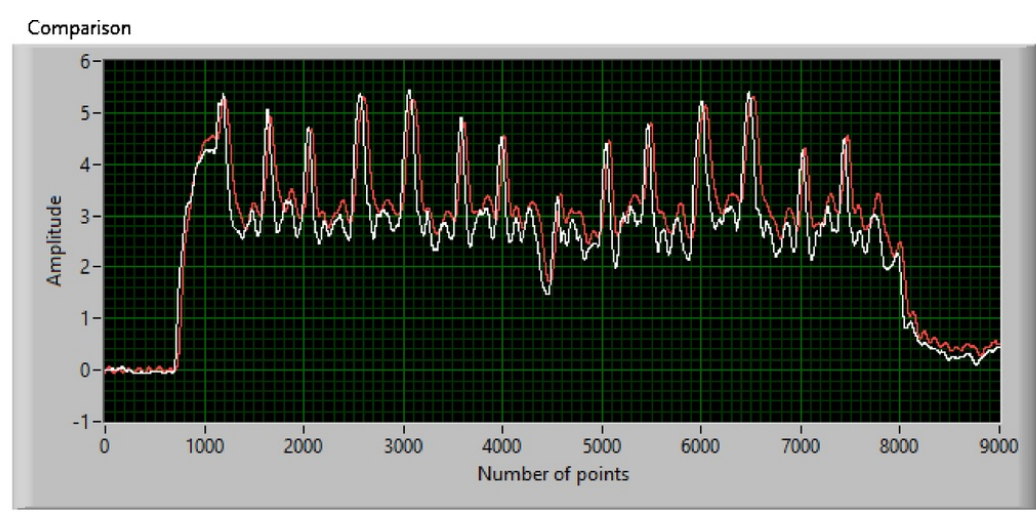

(a)
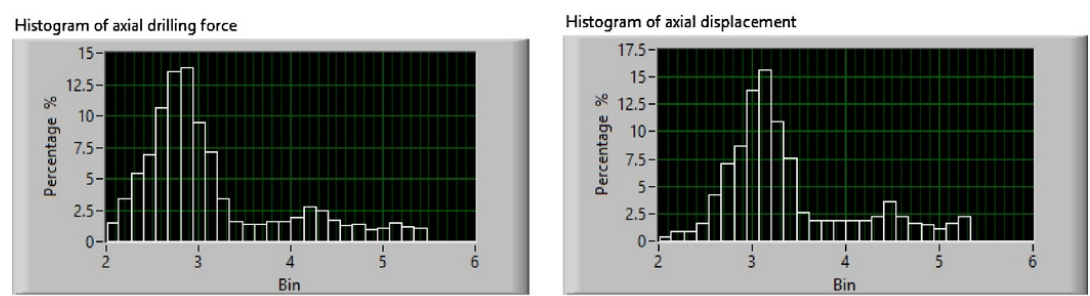

(b)

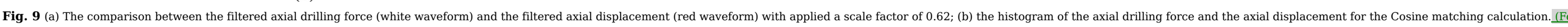
interpretation of the references to colour in this figure legend, the reader is referred to the web version of this article.)

\section{alt-text: Fig. 9}

\subsection{Spindle protection and drilling tool wear monitoring based on the axial shaft displacement}

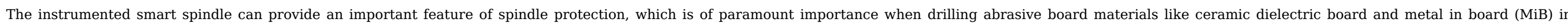

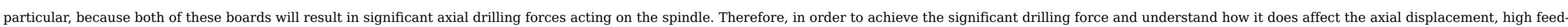
rate parameters are used in machining trials.

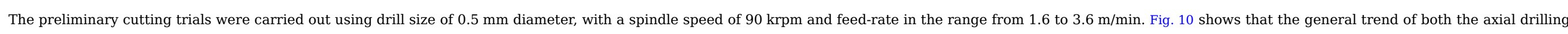

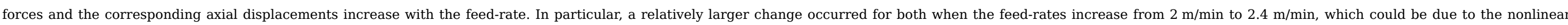

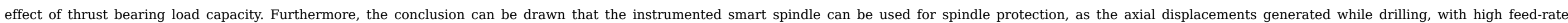
parameters up to $3.6 \mathrm{~m} / \mathrm{mins}$ in these preliminary cutting trials, were not even close to half of the designed air film clearance. 


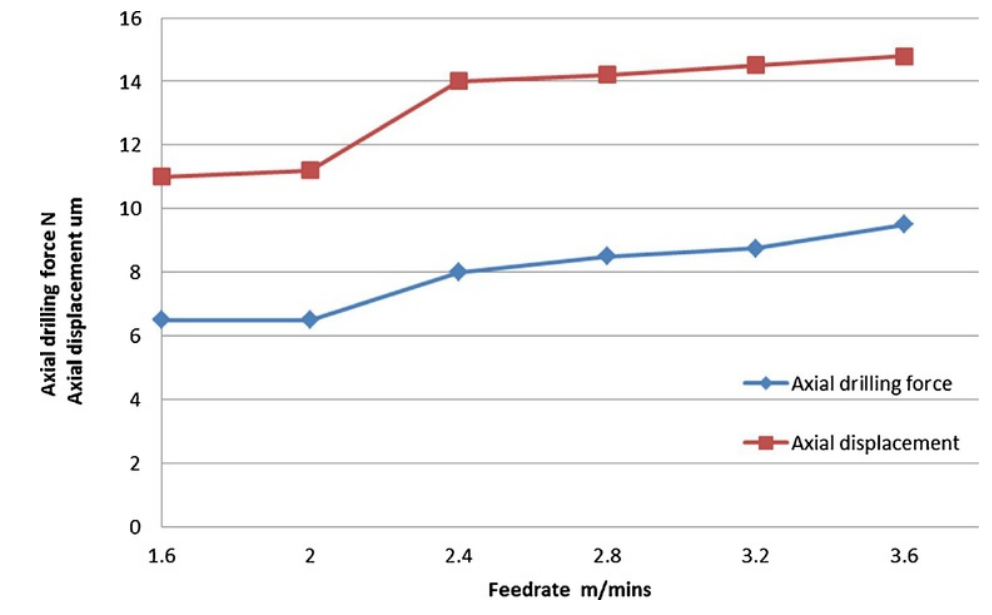

Fig. 10 The axial drilling force and axial displacement measured by the Kistler dynamometer and the instrumented smart spindle with a wide range of feed-rate parameters.

\section{alt-text: Fig. 10}

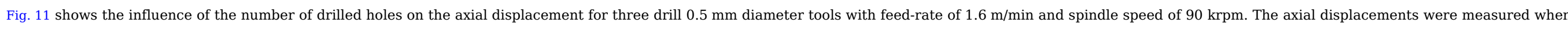

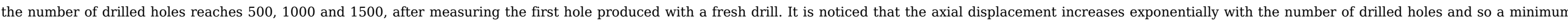

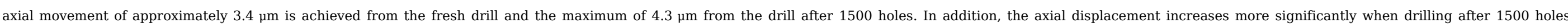

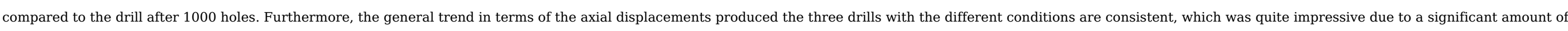
debris produced in a real PCB drilling environment.

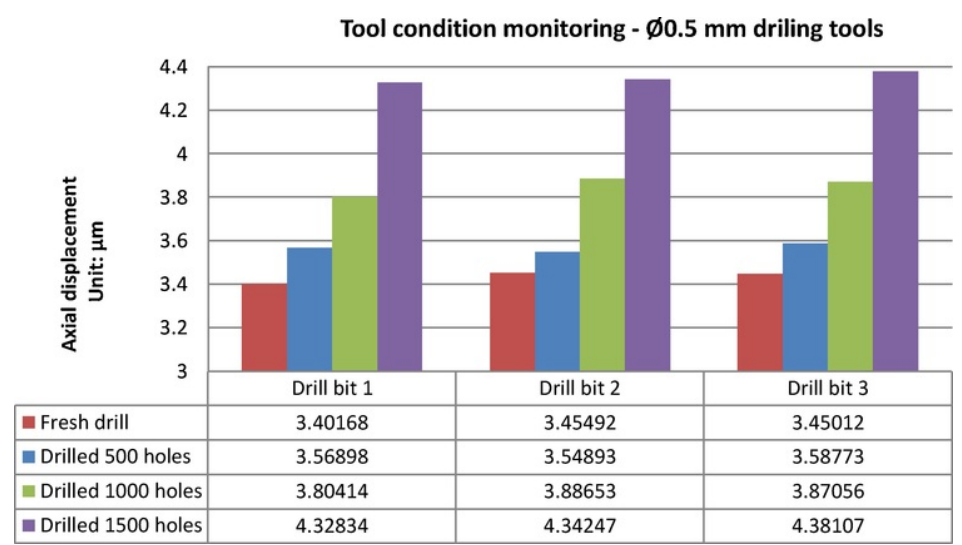

Fig. 11 The influence of the number of drilled holes on the axial displacement using three drilling tools of $0.5 \mathrm{~mm}$ in diameter (feed-rate $=1.6 \mathrm{~m} / \mathrm{min}$ and spindle speed $=90 \mathrm{krpm}$ ). alt-text: Fig. 11

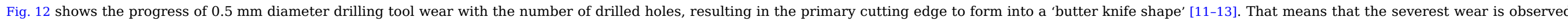

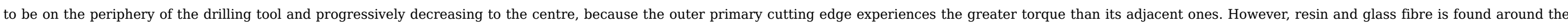

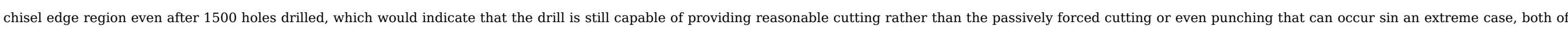

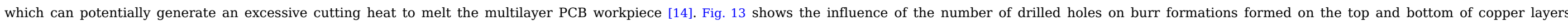




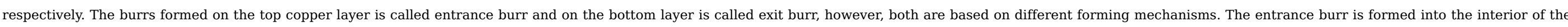

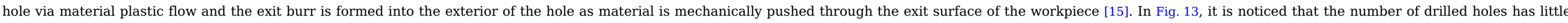

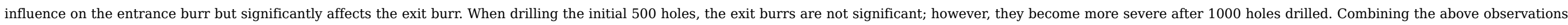

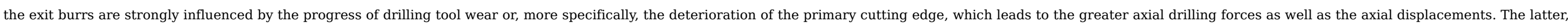
as shown in Fig. 11, demonstrates the increasing trend of the axial displacement with the number of drilled holes.

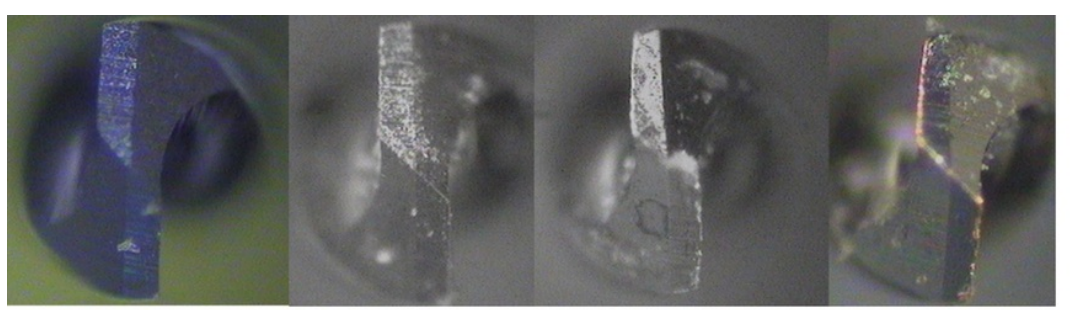

(1) fresh drilling tool (2) drilled 500 holes (3) drilled 1000 holes (4) drilled 1500 holes

Fig. 12 The progress of drilling tool wear with the number of drilled holes (feed-rate $=1.6 \mathrm{~m} / \mathrm{min}$ and spindle speed $=90 \mathrm{krpm}$ ).

alt-text: Fig. 12

The top copper layer (entrance burr)
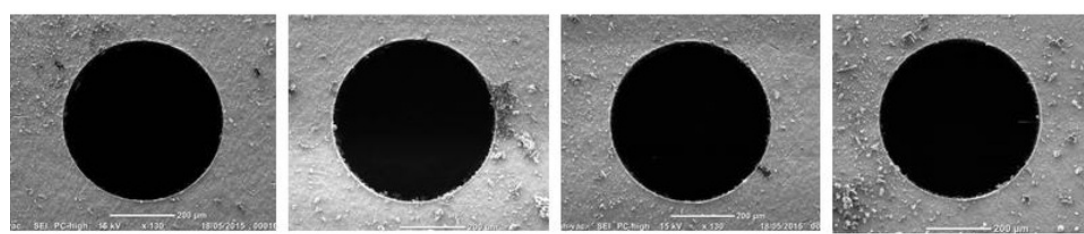

The bottom copper layer (exit burr)

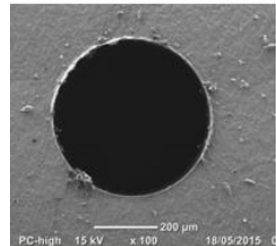

Fresh drilling tool

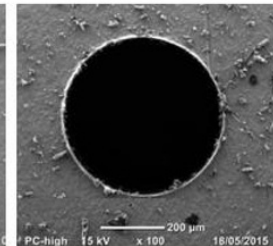

Drilled 500 holes

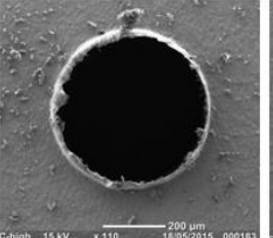

Drilled 1000 holes

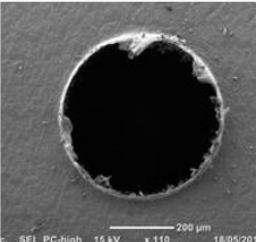

Drilled 1500 holes

Fig. 13 SEM photos showing the influence of the number of drilled holes on the hole quality in terms of burr formation (feed-rate $=1.6 \mathrm{~m} / \mathrm{min}$ and spindle speed $=90 \mathrm{krpm}$ ). alt-text: Fig. 13

\subsection{Nonlinear effect of thrust air bearing on the axial displacement measurement}

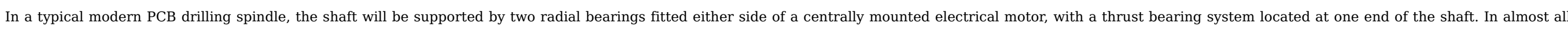

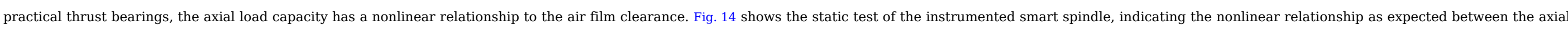

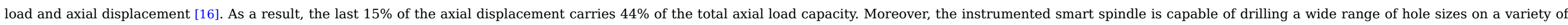

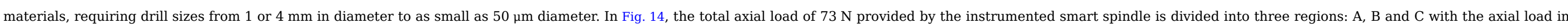

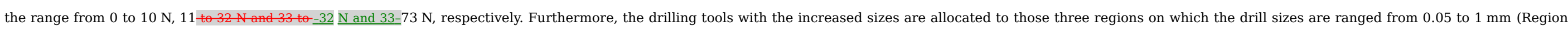

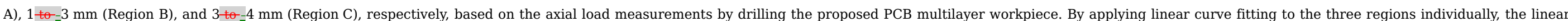




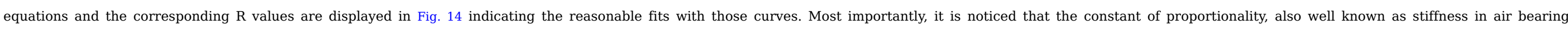

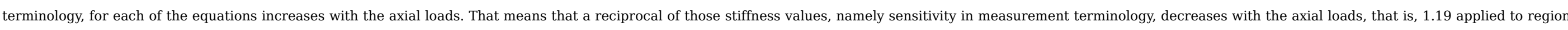

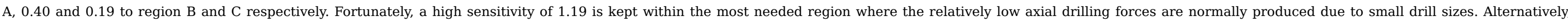

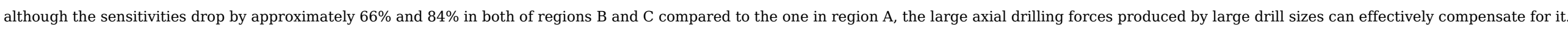

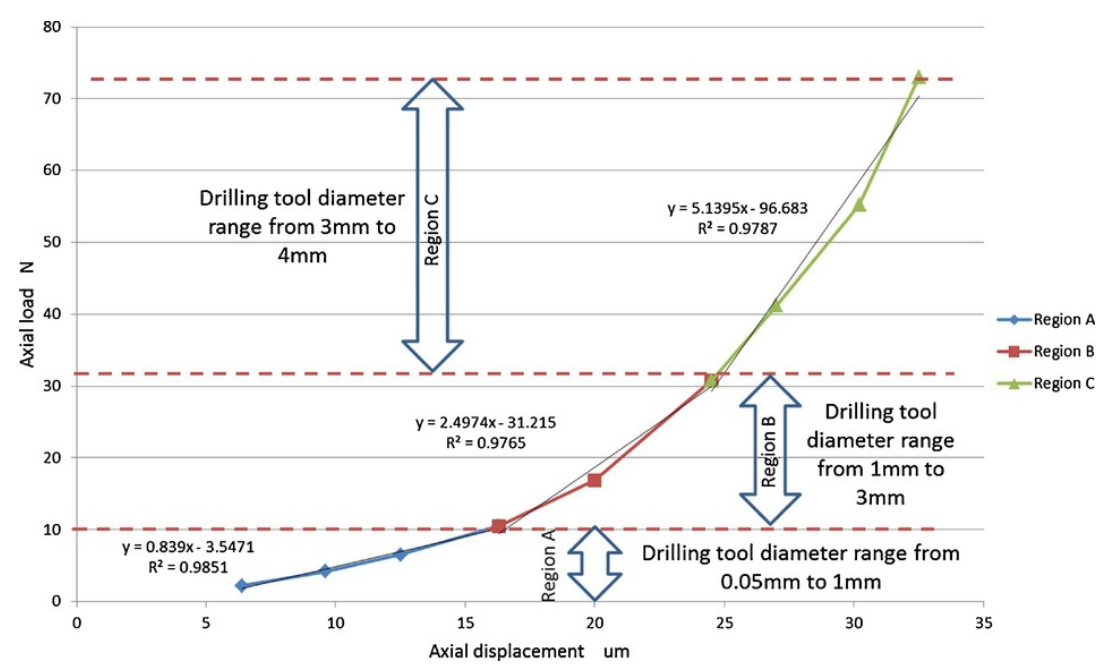

Fig. 14 The nonlinear relationship of the thrust bearing between the axial displacement and the axial load in the static test. alt-text: Fig. 14

\section{Conclusions}

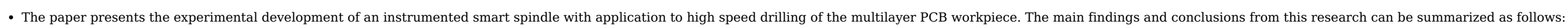

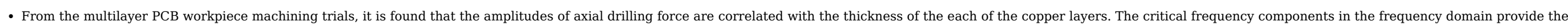
evidence.

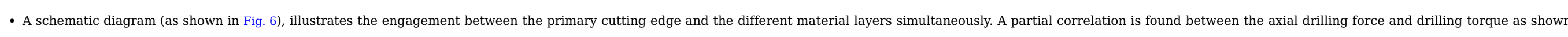

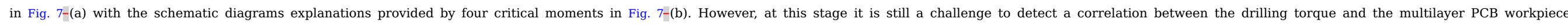
configuration.

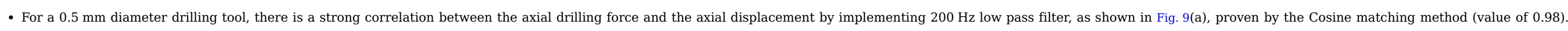
Moreover, the instrumented smart spindle is capable of detecting each of copper layers through measuring the axial displacement.

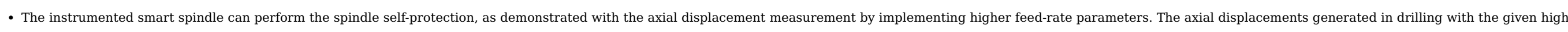
feed-rate parameters up to $3.6 \mathrm{~m} / \mathrm{min}$ were not even close to half of the designed air bearing film clearance.

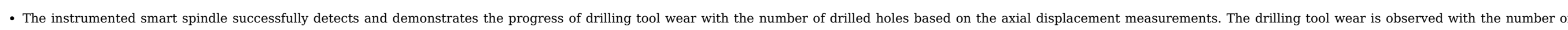

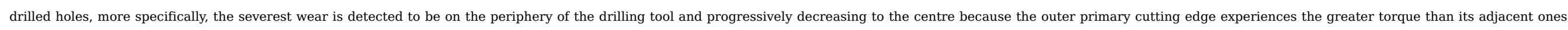
Consequently, hole quality in terms of burr formation deteriorates with the number of drilled holes.

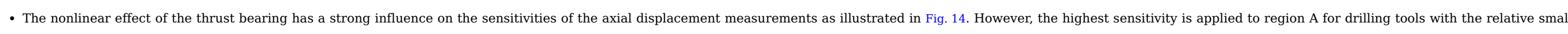

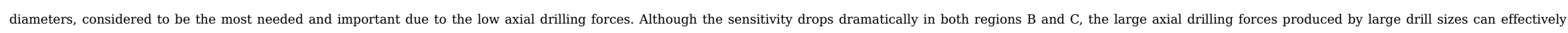


compensate for the sensitivity loss.

\section{Acknowledgements}

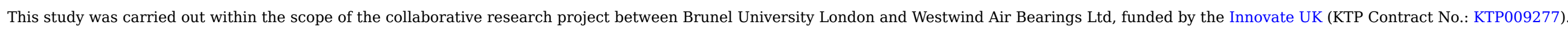
The authors acknowledge many useful discussions within the project team.

\section{References}

[1] E. Abele, Y. Altintas and C. Brecher, Machine Fool Spindle UnitsCIRP Annals Manufacturing Technologytool spindle units, CIRP Ann Manuf Technol 57, $2010,781-802$.

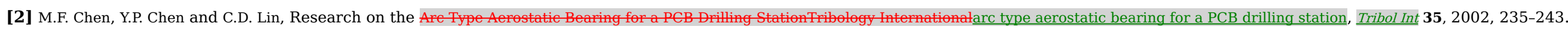

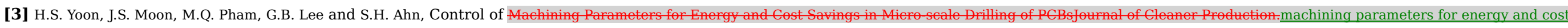
savings in micro-scale drilling of PCBs, ICleaner Prod 54, 2013, 41-48.

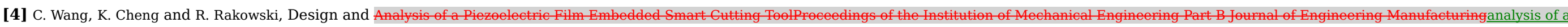
piezoelectric film embedded smart cutting tool, Proc Inst Mech Eng Part B J Eng Manuf 227, 2012, 254-260.

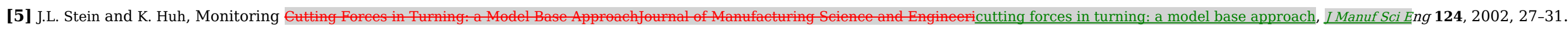

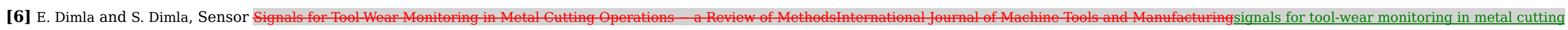
operations -a review of methods, Int J Mach Tools Manuf 40, 1999, 1073-1098.

[7] K. Cheng and D. Huo, Micro eutting: Fundamentals and Acutting: fundamentals and applications, 2013, John Wiley \& Sons Ltd.

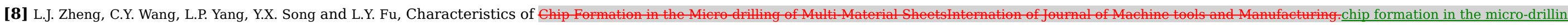
of multi-material sheets, Int. J. Mach. Tools Manuf 52, 2012, 40-49.

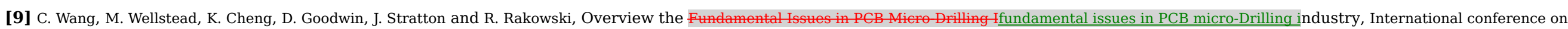
MicroManufacturing (4 M/ICOMM2015), Milan Italy, 2015.

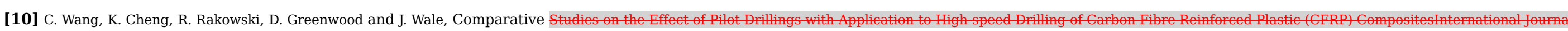

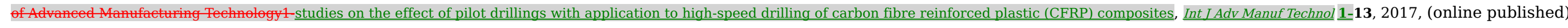

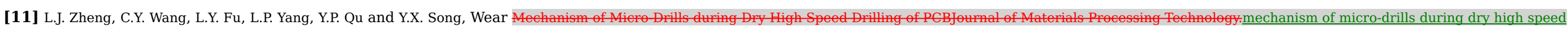
drilling of PCB, IMater Process Technol 212, 2012, 1989-1997.

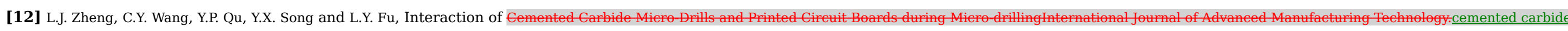
micro-drills and printed circuit boards during micro-drilling, Int J Adv Manuf Technol 77, 2014, 1305-1314.

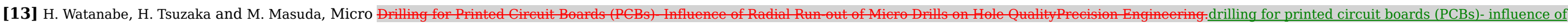
radial run-out of micro drills on hole quality, Precis Eng 32, 2008, 329-335.

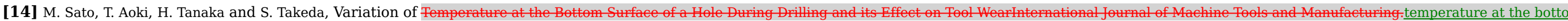
surface of a hole during drilling and its effect on tool wear, Int J Mach Tools Manuf $68,2013,40-47$.

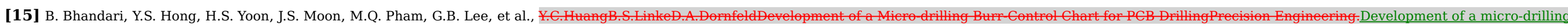
burr-control chart for PCB drilling, Precis Eng 38, 2014, 221-229. 


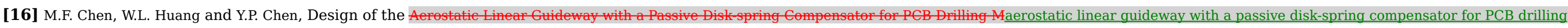
machining, Tribology Internationat Int 43, 2010, 395-403.

\section{Queries and Answers}

Query: The author names have been tagged as given names and surnames (surnames are highlighted in teal color). Please confirm if they have been identified correctly. Answer: Yes

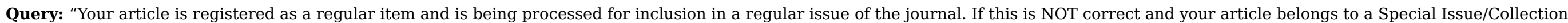
please contact s.jayan@elsevier.com immediately prior to returning your corrections."

Answer: Yes, this article was submitted as a regular issue if the journal.

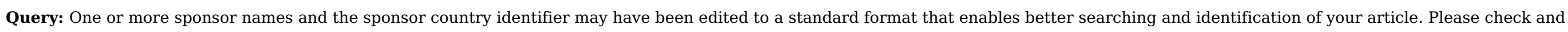
correct if necessary.

Answer: Yes

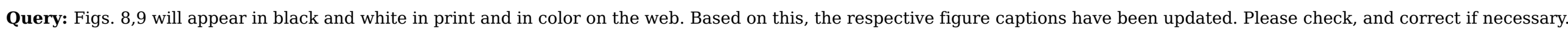
Answer: Yes, both figures are acceptable in B\&W print 